\title{
Breast Radiotherapy and Early Adverse Cardiac Effects. The Role of Serum Biomarkers and Strain Echocardiography
}

\author{
ARETI GKANTAIFI ${ }^{1}$, CHRISTODOULOS PAPADOPOULOS ${ }^{2}$, DESPOINA SPYROPOULOU ${ }^{3}$, \\ MARIA TOUMPOURLEKA ${ }^{4}$, GEORGE ILIADIS ${ }^{1}$, DIMITRIOS KARDAMAKIS ${ }^{3}$, \\ MICHAIL NIKOLAOU $^{5}$, NIKOLAOS TSOUKALAS ${ }^{6}$, GEORGE KYRGIAS $^{7}$ and MARIA TOLIA ${ }^{7}$ \\ ${ }^{1}$ Radiotherapy Department, Interbalkan Medical Center, Thessaloniki, Greece; \\ ${ }^{2} 3$ rd Cardiology Department, Hippokration University Hospital, \\ Aristotle University of Thessaloniki, Thessaloniki, Greece; \\ ${ }^{3}$ Department of Radiation Oncology, Medical School, University of Patras, Patras, Greece; \\ ${ }^{4}$ Second Propedeutic Department of Internal Medicine, Hippokration Hospital, Medical School, \\ Aristotle University of Thessaloniki, Thessaloniki, Greece; \\ ${ }^{5}$ Oncology Clinic, Hippokration University Hospital of Athens, Athens, Greece; \\ ${ }^{6}$ Oncology Department, Veterans Hospital (NIMTS), Athens, Greece; \\ ${ }^{7}$ School of Health Sciences, Department of Radiotherapy, Faculty of Medicine, \\ Biopolis, University of Thessaly, Larissa, Greece
}

\begin{abstract}
Breast cancer radiotherapy has a clear benefit for both long-term survival and local recurrence rate. However, there is still much concern about the early radiation-induced heart toxicity. This article aimed to clarify the impact of certain cardiac biomarkers and strain echocardiographic imaging on the detection of early cardiac dysfunction. Several studies that reported changes in either echocardiographic and/or serum levels measurements after breast radiotherapy were searched. Despite the established role of cardiac biomarkers to predict late cardiotoxicity after radiotherapy, data concerning early cardiac damage are still lacking. Furthermore, although strain echocardiography represents a specific tool for the detection of cardiac morbidity in certain diseases, much interest concerns its role in the prediction of early heart failure after radiotherapy. Identification of new tools for the detection of early cardiotoxicity after breast radiotherapy may minimize the side-effects of therapeutic modalities in the clinical setting.
\end{abstract}

This article is freely accessible online.

Correspondence to: Areti Gkantaifi, MD, Radiotherapy Department, Interbalkan Medical Center, 10 Asclepiou Str, 57001 Pylaia, Thessaloniki, Greece. Tel: +30 2310400192, +30 6932237285, e-mail: aretigk1@yahoo.gr

Key Words: Breast cancer, radiotherapy, cardiotoxicity, biomarkers, echocardiography.
Radiotherapy constitutes one of the most effective management methods for solid malignancies. Data from the Global cancer statistics (GLOBOCAN) indicate that there will be about 18.1 million new cancer cases worldwide in 2018 (1). Among these patients, more than 2 million will suffer from breast malignancies. There is no doubt that radiotherapy accompanied by other therapeutic modalities, including surgery and chemotherapy, has greatly contributed to reduced local recurrences and increased long-term survival rates for these patients (2). Although the major benefit of adjuvant radiotherapy in the local control of the disease is well established, many questions remain regarding the treatment-associated heart toxicity, which may adversely affect the quality of life of cancer survivors (3). Cardiac toxicity after breast cancer radiotherapy results from the exposure of a substantial volume of the heart to a dose, which is capable of adversely affecting the heart tissue. However, whether this could be averted by the most advanced radiation techniques still remains uncertain. Modern radiotherapeutic techniques and advances in treatment planning achieve reduced cardiac radiation exposures with the use of respiratory gating or blocking the heart in tangential field. Nevertheless, these contemporary newer techniques may still affect, to some degree, part of the heart, including the left ascending artery, increasing, thus, the risk of heart disease (4).

Several studies analyzed and confirmed the association between the radiation dose to heart and the increased risk of 
heart disease (5-7). Available data suggest that as the dose of radiation rises, the risk of developing heart complications rises too. Specifically, patients with left side breast cancer clearly present higher possibility to develop cardiac events in comparison with right- sided cancers, while those with previous cardiac disease history obviously have an increased risk of heart damage, which can be observed even by exposure to low radiation doses $(8,9)$. In addition to the dose and the irradiated volume of the heart, the administration of certain chemotherapeutic agents comprises an additional risk factor of cardiotoxicity (10). However, patient-related factors that may also accelerate the development of radiationinduced cardiotoxicity consist of: younger age at radiotherapy, history of circulatory disease, diabetes and some known harmful lifestyle factors such as obesity, lack of activity, alcohol, smoking and hypertension (11).

The cardiotoxic effect of RT can be seen several years after irradiation and the increased risk may remain for at least two decades past radiotherapy (9). Various published data on radiation-induced heart disease have clearly highlighted the unfavorable impact of radiation on the heart tissue many years after radiotherapy, thus, influencing, the lifestyle of long-term cancer survivors $(12,13)$. Consequently, a prolonged followup seems mandatory for the observation of radiation induced cardiac events. Pericarditis, valvular dysfunction, cardiomyopathy and coronary artery disease are some of the severe late cardiotoxic effects, making the incidence of radiation-induced heart disease to be between $10-30 \%$ within 5-10 years following irradiation (14).

\section{Materials and Methods}

We included any paper offering any data concerning strategies and measures for detecting early cardiotoxicity after breast radiotherapy in women treated for left breast cancer. Electronic databases were searched using synonyms for radiation therapy, cardiotoxicity, biomarkers and echocardiography in women with breast cancer. A filter was not used since any type of study was considered, without restriction to randomized controlled trials. PubMed, Cochrane Database of Controlled Trials, and SCOPUS were searched from 1993 to 2018 and with no language restrictions. Cross references from the included studies were hand searched. All titles and abstracts retrieved were printed and reviewed manually by two reviewers independently. The studies that clearly did not meet the inclusion criteria were excluded.

\section{Impact of Radiation Dose on the Heart}

Despite considerable uncertainty, it seems that cardiac effects of radiation are fairly dependent on both dose and fractionation of radiotherapy. In earlier studies it was noted that a radiation dose of $30 \mathrm{~Gy}$ might be the threshold dose for developing heart damage (15). In particular, patients who had received doses lower than 30 Gy for Hodgkin disease, presented much lower incidence of developing pericarditis.
Furthermore, one recent population control study including more than 2,000 women who were treated for breast cancer, highlighted that even extremely low radiation doses may adversely affect the heart tissue (16). Characteristically, it was observed that the risk of developing major coronary events increases linearly by 7.4 percent per one gray of radiation, with a mean radiation dose to the heart being $4.9 \mathrm{~Gy}$. More specifically, this risk may be elevated for at least twenty years after irradiation and is related to the coexistence of other risk factors, such as circulatory and vascular disease. Moreover, a recent large meta-analysis including 39 studies with breast cancer survivors, revealed a higher risk of coronary disease and mortality during the first and second decade respectively, after radiation exposure (17). Nevertheless, the absolute risk seems to be too low to be able to offset the benefit of radiation. An even smaller cohort investigating the dose of radiation in the heart tissue, characteristically demonstrated a significant association between higher radiation dose and higher frequency of cardiac outcomes (18). Notably, they found that the risk of a coronary event increases by $16.5 \%$ per gray of radiation to the heart tissue, with the dose of 5 Gy to the left ventricle being the most predictive component.

However, despite improved treatment modality and different cardiac-sparing techniques, such as enhanced inspiration gating (EIG), deep inspiration breath hold (DIBH) and intensity-modulated radiotherapy (IMRT), there is still a risk of cardiac toxicity after breast radiotherapy (19). Consequently, according to the Quantec (Quantitative Analysis of Normal Tissue Effects in the Clinic-) guidelines, the whole organ of the heart should always be contoured as an organ at risk for left-sided breast cancer at each treatment planning (20). Specifically, the dose of 25 Gy must not affect more than $10 \%$ of the whole heart volume, while the mean heart dose must be kept lower than 26 Gy for standard fractionated radiotherapy. Furthermore, with regard to partial irradiation, it is estimated that by following classic fractionated radiotherapy the risk of cardiac mortality is lower than 1 percent for 15 years when one tenth of the whole heart volume receives less than 25 Gy (21). Nonetheless, given the fact that there is still a lack of studies about the radiation effect on different substructures of the heart, in the era of personalized medicine, the definition of more specific components regarding the association between radiation dose volume parameters and subsequent toxicity constitutes one of the biggest challenges.

\section{Early Cardiotoxicity}

Although much research has already been focused on the analysis of late radiation effects on the heart, more information is still needed concerning the early radiation toxicity, whose clinical assessment still remains difficult. 
Actually, the early identification of radiation damage to the heart tissue might prove to be vital for the improvement of the quality of life of the breast cancer survivors. Therefore, specific cardiac serum biomarkers and strain rate imaging may play a significant role in the detection of early subclinical cardiac changes. Thus, those patients who are at a higher risk and may need close follow-up in order to achieve better outcomes, will be identified.

\section{Serum Biomarkers}

Serum biomarkers might play an important role in the detection of heart damage after radiotherapy. Several classical biomarkers have already been studied for their impact on the discovery of cardiac dysfunction after radiotherapy. Cardiac Troponin I (TnI) and cardiac Troponin T (TnT) are sensitive and specific markers of cardiac morbidity. During the past years, many researchers have extensively studied the significant role of $\mathrm{TnI}$ and $\mathrm{TnT}$ as useful biomarkers of cardiotoxicity in oncologic patients after chemotherapy (22, 23). However, data regarding the value of these cardiac markers after breast radiotherapy are missing. Furthermore, brain natriuretic peptide (BNP) and its amino-terminal fragment (NT pro-BNP) are natriuretic hormones that are released from the heart into the circulation, predicting heart failure (24). Many studies revealed increased levels of these peptides after radiotherapy, which suggests that these proteins can become potential markers for the early detection of radiation-induced cardiotoxicity. Characteristically, in 1995 Hughes-Davies L et al. enrolled 50 patients with left breast cancer aiming to investigate the potential elevation of TnT levels during radiotherapy (25). However, they found no differences comparing the concentration of the protein before and after irradiation. Furthermore, Nellessen et al. analyzed the cardiac biomarkers TnI and BNP before and during the first week of radiotherapy (26). Although they showed elevated levels of both cardiac biomarkers after radiotherapy, the outcomes were not characterized clinically significant. In agreement with the foregoing, D'Errico et al. found no changes in the levels of TnT in left-sided breast cancer patients 5 to 22 months after radiotherapy. Nevertheless, they clearly demonstrated increased levels of NT-pro BNP (27). On the contrary, Erven et al. found elevated mean levels of $\mathrm{TnI}$ in 51 left-sided breast cancer patients after irradiation (28). In line with the above, one recent prospective, nonrandomized study revealed a positive correlation between increased TnT levels and higher radiation dose for the whole heart and the left ventricle in 58 left-sided breast cancer patients (29). As a matter of fact, these outcomes attract a great deal of interest on whether elevated levels of the abovementioned biomarkers after breast radiotherapy could be related to an increased risk of developing cardiovascular morbidity in the near future.
Moreover, since radiation has a tendency of motivating inflammatory processes, $\mathrm{C}$ - reactive protein (CPR), an acute phase protein, whose expression is related to inflammatory cytokines such as interleukin (IL)-1, IL-6 and tissue necrosis factor-a (TNF-a), may be an additional potential predictive marker of cardiotoxicity after irradiation. Many studies have previously highlighted the strong association between elevated levels of high-sensitivity C-reactive protein (hsCRP) and adverse prognosis in patients with heart failure (30-32). Although numerous studies have examined the potential clinical value of CRP measurements in the detection of cardiotoxicity in patients after chemotherapy, there is lack of data about the established role of CRP in the early prediction of myocardial changes. Indeed, Morris et al., after measuring cardiac Troponin I (cTnI) and CRP levels in 95 breast cancer patients during their chemotherapeutic schema, found no relationship between these biomarkers and changes in left ventricular ejection fraction (LVEF) (33). Moreover, two further studies aimed to illustrate the value of cardiac biomarkers as a most promising tool to predict early cardiac injury in patients after chemotherapy $(34,35)$. They similarly found no significant association between elevated levels of CRP and early echocardiographic changes. On the contrary, Lipshultz et al. enrolling 201 childhood cancer survivors demonstrated a higher clinical value of CRP. In particular, increased levels of this protein were found to be related to lower levels of left ventricular (LV) mass, regardless of prior exposure to cardiotoxic therapy (36).

According to these findings, it seems that despite the variability of outcomes, certain serum biomarkers may represent a promising tool for the prediction of early myocardial dysfunction, leading to a more appropriate stratification of those patients who demand closer monitoring. Nevertheless, further studies with more specific biomarkers are certainly needed to empower this association. Therefore, this could lead to a deep and multidisciplinary comprehension of all the potential biological mechanisms involved in heart dysfunction after radiotherapy, so that patients receive the greatest benefit possible.

\section{Strain Rate Imaging}

Speckle tracking echocardiography may be used as a valuable tool for the quantification of regional myocardial function, which could be proven vital, taking into account the association between abnormalities of the left ventricle and lower survival rates (37). Specifically, strain and strain rate imaging calculated by 2 -dimensional speckle tracking echocardiography (2D-STE) might constitute a highly specific clinical approach for the detection of early subclinical abnormalities of the heart tissue. Indeed, by measuring myocardial viability, these parameters could be used for the assessment of early myocardial damage (38-40). 
Several studies have well defined the superiority of strain imaging over LVEF regarding the evaluation of left ventricular function, thus highlighting the higher prognostic value of the aforementioned and accordingly its ability to show which patients have a higher risk of developing heart damage in the near future $(41,42)$. Furthermore, a lot of studies have already proposed the role of strain imaging in revealing subclinical heart damage in various conditions. For instance, Kato et al. previously calculated strain and strain rate parameters in 50 patients in order to illustrate the sensitivity of this method to adequately differentiate hypertrophic cardiomyopathy (HCM) from hypertensive left ventricular hypertrophy (H-LVH) (43). A more recent study led to similar results some years later (44). Moreover, it was well shown that strain imaging can effectively detect subclinical left ventricular changes in diabetic patients $(45$, 46). Apart from that, many investigators have also demonstrated the relationship between strain imaging and the detection of early heart dysfunction after the administration of chemotherapeutic agents. Actually, Stoodley et al. found reduced post-chemotherapy strain parameters in 52 women with breast cancer; the capacity of strain imaging to predict early cardiotoxicity was also confirmed by Sawaya et al. one year later $(47,48)$. More recent studies also supported the decrease of strain parameters after chemotherapy, hence, declaring the potential ability of this method to predict early dysfunction of the heart tissue $(49,50)$.

Although several researchers have examined the potential role of strain imaging in revealing myocardial changes in several diseases, only few succeeded to investigate the impact of these parameters on the detection of the early heart damage in breast cancer patients after radiotherapy. Specifically, Wang et al. assessed early heart changes after thoracic radiotherapy by analyzing various data of strain rate in the left ventricular walls (51). Notably, they separated40 patients into three groups according to the time of the radiotherapeutic process: 1-3 days before radiotherapy, 2-3 weeks and 5-6 weeks during radiotherapy, respectively. What they observed was that the lowest strain and conventional echocardiographic parameters were found among patients with the longest duration and highest dose of radiotherapy, demonstrating, that strain rate imaging can successfully indicate early radiation cardiac effects. Similar results have also been illustrated by Chang et al. in 40 patients a few years later, highlighting the value of strain rate imaging in the detection of early cardiac dysfunction after thoracic radiotherapy (52). Specifically, by dividing patients into 5 groups according to dose and duration of radiotherapy, they evaluated all the echocardiographic and strain rate data. As a result, they detected a significant relationship between longer duration and higher dose of radiotherapy and lower strain rate and echocardiographic parameters, declaring that strain rate may reveal earlier the radiation induced heart damage in patients who have had previous thoracic radiotherapy. Similarly, to the previous observations, Tsai et al. demonstrated lower left ventricular systolic function and strain rate parameters in 47 patients at least two decades after previous thoracic radiotherapy with or without chemotherapy (53).

Moreover, the same year, Erven et al. published their data about the role of strain rate imaging in revealing early myocardial dysfunction after breast cancer radiotherapy (54). In particular, studying the changes of strain parameters in 20 patients with left breast cancer and 10 with right breast before radiotherapy, at the end of it and after two months, they characteristically found reduced post-radiation strain and strain rate levels in all patients with left breast cancer. More recently, a further study conducted by the same researcher also confirmed decreased strain measurements, mainly in anterior segments, in 51 patients with left-sided breast cancer 8 and 14 months after radiotherapy (28). Two years later, Lo et al. showed that the strain parameters remained decreased 6 weeks after the end of radiotherapy in 40 women with left-sided breast cancer, thus, stressing the possibly severe role of 2dimensional strain imaging (SI) in the early detection of left ventricular dysfunction (55). Finally, quite different results have been reported by Heggemann et al. in 49 patients where they demonstrated reduced measurements of longitudinal strain in some segments, but also, stabilized global strain levels 24 months after radiotherapy (56). Thereafter, it seems to be clear that strain rate echocardiography may successfully reveal early subclinical cardiac abnormalities after radiotherapy in some subregions of the heart.

In conclusion, it appears that early negative effects on the heart and specifically on the myocardium and left ventricle may be detected by strain echocardiographic imaging. Many studies clearly demonstrated decreased levels of strain parameters after radiotherapy promoting this approach as a promising method for the better quantification of early changes in heart function after radiotherapy. However, much more systematic research with larger studies and longer follow-up is surely required for an improved assessment and exploitation of this sensitive echocardiographic tool regarding the field of cardiotoxicity after radiotherapy.

\section{Conclusion}

Breast cancer constitutes the most frequent type of neoplastic disease among females, a fact that arises major concern regarding the potential effects of the whole therapeutic management, which is required on a case-by-case basis. During the last two decades the relationship between breast radiotherapy and late toxicity of the heart tissue has been extensively described. However, taking into account the high survival rate of breast cancer patients and subsequently how important it is for these patients to reduce morbidity to a minimum, much information is further needed for the 
establishment of the most appropriate methods that could early predict those who are at a higher risk. Actually, several biomarkers have been well documented for their relation to the prediction of heart changes after radiotherapy. Nevertheless, there is still a lack of robust results regarding the establishment of characteristic biomarkers capable of revealing early cardiotoxicity. Thus, an intensive evaluation of the changes of specific cardiac biomarkers during a longer follow up after radiotherapy might be a highly useful tool for the early detection of potential toxicity to different subregions of the heart. In addition, conventional echocardiography has been widely used for the assessment of radiation-induced cardiotoxicity for more than two decades. However, stain imaging seems to be a more sensitive method for the evaluation of heart function after radiotherapy, which has already been reported by certain studies. Nonetheless, further research is certainly required for the establishment of this promising echocardiographic parameter as a valuable method for the detection of heart failure early after radiotherapy. Accordingly, this could enhance the management of breast cancer patients and improve their quality of life.

In conclusion, it is imperative that prevention and early diagnosis of post-radiation heart toxicity is the priority of the whole therapeutic process. Thereafter, novel ideas based on this aim are considered fruitful leading to more appropriate therapeutic techniques individually for each patient.

\section{Conflicts of Interest}

The Authors declare that they have no conflicts of interest.

\section{Authors' Contributions}

All the Authors have participated in the writing and revision of this article and take responsibility for its content. The present publication is approved by all Authors and by the responsible authorities where the work was carried out. The Authors confirm that the content of the manuscript has not been published, or submitted for publication elsewhere.

\section{References}

1 Bray F, Ferlay J, Soerjomataram I, Siegel RL, Torre LA and Jemal A: Global cancer statistics 2018: GLOBOCAN estimates of incidence and mortality worldwide for 36 cancers in 185 countries. CA Cancer J Clin 68: 394-424, 2018. PMID: 30207593. DOI: $10.3322 /$ caac. 21492

2 Kesson EM, Allardice GM, George WD, Burns HJ and Morrison DS: Effects of multidisciplinary team working on breast cancer survival: retrospective, comparative, interventional cohort study of 13722 women. BMJ 344: e2718, 2012. PMID: 22539013. DOI: $10.1136 /$ bmj.e2718

3 Clarke M, Collins R, Darby S, Davies C, Elphinstone P, Evans V, Godwin J, Gray R, Hicks C, James S, MacKinnon E, McGale $\mathrm{P}$, McHugh T, Peto R, Taylor $\mathrm{C}$ and Wang Y: Effects of radiotherapy and of differences in the extent of surgery for early breast cancer on local recurrence and 15-year survival: an overview of the randomised trials. Lancet 366: 2087-2106, 2005. PMID: 16360786. DOI: 10.1016/S0140-6736(05)67887-7

4 Travis LB, Ng AK, Allan JM, Pui CH, Kennedy AR, Xu XG Purdy, JA, Applegate K, Yahalom J, Constine LS, Gilbert ES and Boice JD Jr.: Second malignant neoplasms and cardiovascular disease following radiotherapy. J Natl Cancer Inst 104: 357-370, 2012. PMID: 22312134. DOI: $10.1093 /$ jnci/djr533

5 Carr ZA, Land CE, Kleinerman RA, Weinstock RW, Stovall M, Griem ML and Mabuchi K: Coronary heart disease after radiotherapy for peptic ulcer disease. Int J Radiat Oncol Biol Phys 61: 842-850, 2005. PMID: 15708264. DOI: 10.1016/ j.ijrobp.2004.07.708

6 Aznar MC, Korreman SS, Pedersen AN, Persson GF, Josipovic $\mathrm{M}$ and Specht L: Evaluation of dose to cardiac structures during breast irradiation. Br J Radiol 84: 743-746, 2011. PMID: 21159806. DOI: $10.1259 / \mathrm{bjr} / 12497075$

7 Lohr F, El-Haddad M, Dobler B, Grau R, Wertz HJ, KrausTiefenbacher U, Steil V, Madyan YA and Wenz F: Potential effect of robust and simple IMRT approach for left-sided breast cancer on cardiac mortality. Int J Radiat Oncol Biol Phys 74: 7380, 2009. PMID: 18973977. DOI: 10.1016/j.ijrobp.2008.07.018

8 Van den Bogaard VA, Ta BD, van der Schaaf A, Bouma AB, Middag AM, Bantema-Joppe EJ, vanDijk LV, van Dijk-Peters FB, Marteijn LA, de Bock GH, Burgerhof JG, Gietema JA, Langendijk JA, Maduro JH and Crijns AP: Validation and modification of a prediction model for acute cardiac events in patients with breast cancer treated with radiotherapy based on three-dimensional dose distributions to cardiac substructures. J Clin Oncol 35: 1171-1178, 2017. PMID: 28095159. DOI: 10.1200/JCO.2016.69.8480

9 Darby SC, Ewertz M, McGale P, Bennet AM, Blom-Goldman U, Brønnum D, Correa C, Cutter D, Gagliardi G, Gigante B, Jensen MB, Nisbet A, Peto R, Rahimi K, Taylor C and Hall P: Risk of ischemic heart disease in women after radiotherapy for breast cancer. N Engl J Med 368: 987-998, 2013. PMID: 23484825. DOI: 10.1056/NEJMoa1209825

10 Meyer RM, Gospodarowicz MK, Connors JM, Pearcey RG, Wells WA, Winter JN, Horning SJ, Dar AR, Shustik C, Stewart DA, Crump M, Djurfeldt MS, Chen BE and Shepherd LE: NCIC Clinical Trials group, Eastern Cooperative Oncology Group. ABVD alone versus radiation-based therapy in limited stage Hodgkin's lymphoma. N Engl J Med 366: 399-408, 2012. PMID: 22149921. DOI: 10.1056/NEJMoa1111961

11 Darby SC, Cutter DJ, Boerma M, Constine, LS, Fajardo LF, Kodama K, Mabuchi K, Marks LB, Mettler FA, Pierce LJ, Trott KR, Yeh ET and Shore RE: Radiation-related heart disease: current knowledge and future prospects. Int J Radiat Oncol Biol Phys 76: 656-665, 2010. PMID: 20159360. DOI: 10.1016/ j.ijrobp.2009.09.064

12 Aleman BM, van den Belt-Dusebout AW, Klokman WJ, Van't Veer MB, Bartelink H and van Leeuwen FE: Long-term causespecific mortality of patients treated for Hodgkin's disease. J Clin Oncol 21: 3431-3439, 2003. PMID: 12885835. DOI: 10.1200/JCO.2003.07.131

13 Darby SC, McGale P, Taylor CW and Peto R: Long-term mortality from heart disease and lung cancer after radiotherapy for early breast cancer: prospective cohort study of about 300,000 women in US SEER cancer registries. Lancet Oncol 6: 557-565, 2005. PMID: 16054566. DOI: 10.1016/S1470-2045(05)70251-5 
14 Carver JR, Shapiro CL, Ng A, Jacobs L, Schwartz C, Virgo KS, Hagerty KL, Somerfield MR and Vaughn DJ: ASCO Cancer Survivorship Expert Panel. American Society of Clinical Oncology clinical evidence review on the ongoing care of adult cancer survivors: cardiac and pulmonary late effects. J Clin Oncol 25: 3991-4008, 2007. PMID: 17577017. DOI: 10.1200/JCO.2007. 10.9777

15 Hancock SL, Tucker MA and Hoppe RT: Factors affecting late mortality from heart disease after treatment of Hodgkin's disease. JAMA 270: 1949-1955, 1993. PMID: 8411552. DOI: 10.1001/jama.1993.03510160067031

16 Moslehi J: The cardiovascular perils of cancer survivorship. N Engl J Med 368: 1055-1056,2013. PMID: 23484833. DOI: 10.1056/NEJMe 1215300

17 Cheng YJ, Nie XY, Ji CC, Lin XX, Liu LJ, Chen XM, Yao H and $\mathrm{Wu} \mathrm{SH}$ : Long-term cardiovascular risk after radiotherapy in women with breast cancer. J Am Heart Assoc 6, 2017. PMID: 28529208. DOI: 10.1161/JAHA.117.005633

18 Van den Bogaard VA, Ta BD, van der Schaaf A, Bouma AB, Middag AM, Bantema-Joppe EJ, van Dijk LV, van Dijk-Peters FB, Marteijn LA, de Bock GH, Burgerhof JG, Gietema JA, Langendijk JA, Maduro JH and Crijns AP: Validation and modification of a prediction model for acute cardiac events in patients with breast cancer treated with radiotherapy based on three-dimensional dose distributions to cardiac substructures. J Clin Oncol 35: 1171-1178, 2017. PMID: 28095159. DOI: 10.1200/JCO.2016.69.8480

19 Korreman SS, Pedersen AN, Josipović M, Aarup LR, JuhlerNøttrup T, Specht L and Nyström H: Cardiac and pulmonary complication probabilities for breast cancer patients after routine end-inspiration gated radiotherapy. Radiother Oncol 80: 257-262, 2006. PMID: 16905210. DOI: 10.1016/j.radonc.2006.07.020

20 Emami B: Tolerance of normal tissue to therapeutic radiation. Rep Radiother Oncol 1: 123-127, 2013.

21 Gagliardi G, Constine LS, Moiseenko V, Correa C, Pierce LJ, Allen AM and Marks LB: Radiation dose volume effects in the heart. Int J Radiat Oncol Biol Phys 76: 77-85, 2010. PMID: 20171522. DOI: 10.1016/j.ijrobp.2009.04.093

22 Cardinale D, Sandri MT, Colombo A, Colombo N, Boeri M, Lamantia G, Civelli M, Peccatori F, Martinelli G, Fiorentini C and Cipolla CM: Prognostic value of troponin I in cardiac risk stratification of cancer patients undergoing high-dose chemotherapy. Circulation 109: 2749-2754, 2004. PMID: 15148277. DOI: 10.1161/01.CIR.0000130926.51766.CC

23 Garrone O, Crosetto N, Lo Nigro C, Catzeddu T, Vivenza D, Monteverde M, Merlano $\mathrm{M}$ and Feola $\mathrm{M}$ : Prediction of anthracycline cardiotoxicity after chemotherapy by bio- markers kinetic analysis. Cardiovasc Toxicol 12: 135-142, 2012. PMID: 22189487. DOI: 10.1007/s12012-011-9149-4

24 Mant J, Doust J, Roalfe A, Barton P, Cowie MR, Glasziou P, Mant D, McManus RJ, Holder R, Deeks J, Fletcher K, Qume M, Sohanpal S, Sanders S and Hobbs FD: Systematic review and individual patient data meta-analysis of diagnosis of heart failure, with modelling of implications of different diagnostic strategies in primary care. Health Technol Assess 13: 1-207, 2009. PMID: 19586584 . DOI: $10.3310 /$ hta 13320

25 Hughes-Davies L, Sacks D, Rescigno J, Howard S and Harris J: Serum cardiac tro- ponin T levels during treatment of early-stage breast cancer. J Clin Oncol 13: 2582-2584, 1995. PMID: 7595710. DOI: $10.1200 / \mathrm{JCO} .1995 .13 .10 .2582$
26 Nellessen U, Zingel M, Hecker H, Bahnsen J and Borschke D: Effects of radiation therapy on myocardial cell integrity and pump function: Which role for cardiac biomarkers? Chemotherapy 56: 147-152, 2010. PMID: 20407242. DOI: 10.1159/000313528

27 D’Errico MP, Grimaldi L, Petruzzelli MF, Gianicolo EA, Tramacere F, Monetti A, Placella R, Pili G, Andreassi MG, Sicari R, Picano E and Portaluri M: N-terminal pro-B-type natriuretic peptide plasma levels as a potential biomarker for cardiac damage after radiotherapy in patients with left-sided breast cancer. Int J Radiat Oncol Biol Phys 82: 239-246, 2012. PMID: 21640499. DOI: 10.1016/j.ijrobp.2011.03.058

28 Erven K, Florian A, Slagmolen P, Sweldens C, Jurcut R, Wildiers $\mathrm{H}$, Voigt JU and Weltens C: Subclinical cardiotoxicity detected by strain rate imaging up to 14 months after breast radiationtherapy. Int J Radiat Oncol Biol Phys 85: 1172-1178, 2013. PMID: 23149005. DOI: 10.1016/j.ijrobp.2012.09.022

29 Skyttä T, Tuohinen S, Boman E, Virtanen V, Raatikainen P and Kellokumpu-Lehtinen PL: Troponin T-release associates with cardiac radiation doses during adjuvant left-sided breast cancer radiotherapy. Radiat Oncol 10: 141, 2015. PMID: 26159409. DOI: 10.1186/s13014-015-0436-2

30 Mueller C, Laule-Kilian K, Christ A, Brunner-La Rocca HP and Perruchoud AP: Inflammation and long-term mortality $n$ acute congestive heart failure. Am Heart J 151: 845-850, 2006. PMID: 16569545. DOI: 10.1016/j.ahj.2005.06.046

31 Windram JD, Loh PH, Rigby AS, Hanning I, Clark AL and Cleland JG: Relationship of high-sensitivity C-reactive protein to prognosis and other prognostic markers in outpatients with heart failure. Am Heart J 153: 1048-1055, 2007. PMID: 17540208. DOI: 10.1016/j.ahj.2007.03.044

32 Arruda-Olson AM, Enriquez-Sarano M, Bursi F, Weston SA, Jaffe AS, Killian JM and Roger VL: Left ventricular function and C-reactive protein levels in acute myocardial infarction. Am J Cardiol 105: 917-921, 2010. PMID: 20346306. DOI: 10.1016/j.amjcard 2009.11 .025

33 Morris PG Chen C, Steingart R, Fleisher M, Lin N, Moy B, Come S, Sugarman S, Abbruzzi A, Lehman R, Patil S, Dickler M, McArthur HL, Winer E, Norton L, Hudis CA and Dang CT: Troponin I and C-reactive protein are commonly detected in patients with breast cancer treated with dose-dense chemotherapy incorporating trastuzumab and lapatinib. Clin Cancer Res 17: 3490-3499, 2011. PMID: 21372222. DOI: 10.1158/1078-0432.CCR-10-1359

34 Lipshultz SE, Miller TL, Scully RE, Lipsitz SR, Rifai N, Silverman LB, Colan SD, Neuberg DS, Dahlberg SE, Henkel $\mathrm{JM}$, Asselin BL, Athale UH, Clavell LA, Laverdière C, Michon $\mathrm{B}$,Schorin MA and Sallan SE: Changes in cardiac biomarkers during doxorubicin treatment of pediatric patients with high-risk acute lymphoblastic leukemia: associations with long-term echocardiographic outcomes. J Clin Oncol 30: 1042-1049, 2012. PMID: 22370326. DOI: 10.1200/JCO.2010.30.3404

35 Ky B, Putt M, Sawaya H, French B, Januzzi JL Jr, Sebag IA, Plana JC, Cohen V, Banchs J, Carver JR, Wiegers SE, Martin RP, Picard MH, Gerszten RE, Halpern EF, Passeri J, Kuter I and Scherrer-Crosbie M: Early increases in multiple biomarkers predict subsequent cardiotoxicity in patients with breast cancer treated with doxorubicin, taxanes and trastuzumab. J Am Coll Cardiol 63: 809-816, 2014. PMID: 24291281. DOI: 10.1016/ j.jacc.2013.10.061 
36 Lipshultz SE, Landy DC, Lopez-Mitnik G, Lipsitz SR,Hinkle AS, Constine LS, French CA, Rovitelli AM, Proukou C, Adams MJ and Miller TL: Cardiovascular status of childhood cancer survivors exposed and unexposed to cardiotoxic therapy. J Clin Oncol 30: 1050-1057, 2012. PMID: 22393080. DOI: 10.1200/ JCO.2010.33.7907

37 Wang TJ, Evans JC, Benjamin EJ, Levy D, LeRoy EC and Vasan RS: Natural history of asymptomatic left ventricular systolic dysfunction in the community. Circulation 108: 977-982, 2003. PMID: 12912813. DOI: 10.1161/01.CIR.0000085166.44904.79

38 Sutherland GR, Di Salvo G, Claus P, D’Hoogem J and Bijnens B: Strain and strain rate imaging: a new clinical approach to quantifying regional myocardial function. J Am Soc Echocardiogr 17: 788-802, 2004. PMID: 15220909. DOI: 10.1016/j.echo. 2004.03.027

39 Gorcsan J 3rd and Tanaka H: Echocardiographic assessment of myocardial strain. J Am Coll Cardiol 58: 1401-1413, 2011. PMID: 21939821. DOI: 10.1016/j.jacc.2011.06.038

40 Chen S, Yuan J, Qiao S, Duan F, Zhang J and Wang H: Evaluation of left ventricular diastolic function by global strain rate imaging in patients with obstructive hypertrophic cardiomyopathy: a simultaneous speckle tracking echocardiography and cardiac catheterization study. Echocardiography 31: 615-622, 2014. PMID:24219240. DOI: 10.1111/echo.12424

41 Kalam K, Otahal P and Marwick TH: Prognostic implications of global LV dysfunction: a systematic review and meta-analysis of global longitudinal strain and ejection fraction. Heart 100: 16731680, 2014. PMID:24860005. DOI: 10.1136/heartjnl-2014305538

42 Russo C, Jin Z, Elkind MS, Rundek T, Homma S, Sacco RL and Di Tullio MR: Prevalence and prognostic value of subclinical left ventricular systolic dysfunction by global longitudinal strain in a community-based cohort. Eur J Heart Fail 16: 1301-1309, 2014. PMID: 25211239. DOI: 10.1002/ejhf.154

43 Kato TS, Noda A, Izawa H, Yamada A, Obata K, Nagata K, Iwase M, Murohara T and Yokota M: Discrimination of non-obstructive hypertrophic cardiomyopathy from hypertensive left ventricular hypertrophy on the basis of strain rate imaging by tissue Doppler ultrasonography. Circulation 110: 3808-3814, 2004. PMID: 15583080. DOI: 10.1161/01.CIR.0000150334.69355.00

44 Minoshima M, Noda A, Nishizawa T, Hara Y, Sugiura M, Iino S, Nagata K, Koike Y and Murohara T: Endomyocardial radial strain imaging and left ventricular relaxation abnormalities in patients with hypertrophic cardiomyopathy or hypertensive left ventricular hypertrophy. Circ J 73: 2294-2249, 2009. PMID: 19838000. DOI: 10.1253/circj.CJ-08-0879

45 Fang ZY, Schull-Meade R, Downey M, Prins J and Marwick TH: Determinants of subclinical diabetic heart disease. Diabetologia 48: 394-402, 2005. PMID: 15645206. DOI: 10.1007/s00125-004-1632-Z

46 Zoroufian A, Razmi T, Taghavi-Shavazi M, Lotfi-Tokaldany M and Jalali A: Evaluation of subclinical left ventricular dysfunction in diabetic patients: longitudinal strain velocities and left ventricular dyssynchrony by two-dimensional speckle tracking echocardiography study. Echocardiography 31: 456463, 2014. PMID: 24134395. DOI: 10.1111/echo.12389

47 Stoodley PW, Richards DA, Hui R, Boyd A, Harnett PR, Meikle SR, Clarke J and Thomas L: Two dimensional myocardial strain imaging detects changes in left ventricular systolic function immediately after anthracyclin chemotherapy. Eur J Echocardiogr 12: 945-952, 2011. PMID: 21965152. DOI: 10.1093/ejechocard/ jer187

48 Sawaya H, Sebag IA, Plana JC, Januzzi JL, Ky B, Tan TC, Cohen V, Banchs J, Carver JR, Wiegers SE, Martin RP, Picard MH, Gerszten RE, Halpern EF, Passeri J, Kuter I and ScherrerCrosbie M: Assessment of echocardiography and biomarkers for the extended prediction of cardiotoxicity in patients treated with anthracyclines, taxanes and trastuzumab. Circ Cardiovasc Imaging 5: 596-603, 2012. PMID: 22744937. DOI: 10.1161/ CIRCIMAGING.112.973321

49 BottinorWJ, Migliore CK, Lenneman CA and Stoddard MF: Echocardiographic assessment of cardiotoxic effects of cancer therapy. Curr Cardiol Rep 18: 99, 2016. PMID: 27566332. DOI: 10.1007/s11886-016-0776-z

50 Gripp EA, Oliveira GE, Feijó LA, Garcia MI, Xavier SS and Sousa AS: Global longitudinal strain accuracy for cardiotoxicity prediction in a cohort of breast cancer patients during anthracycline and/or trastuzumab treatment. Arq Bras Cardiol 110: 140-150, 2018. PMID: 29561992. DOI: 10.5935/abc. 20180021

51 Wang YA, Li GS, Cui HY and Xia DZ: Strain rate imaging in early assessment of thoracic radiotherapy-induced myocardial damage. Chin J Med Imaging Technol 22: 1194-1196, 2006.

52 Chang HF, Jiang ZR, Wang XF and Wang ZN: Strain rate imaging in assessment of the relationship between the dose of thoracic radiotherapy and the radiotherapy-induced myocardial damage. Chin J Med Imaging Technol 25: 1032-1035, 2009.

53 Tsai HR, Gjesdal O, Wethal T, Haugaa KH, Fossa A, Fossa SD and Edvardsen T: Left ventricular function assessed by twodimensional speckle tracking echocardiography in long-term survivors of Hodgkin's lymphoma treated by mediastinal radiotherapy with or without anthracycline therapy. Am J Cardiol 107: 472-477, 2011. PMID: 21257017. DOI: 10.1016/j.amjcard. 2010.09 .048

54 Erven K, Jurcut R, Weltens C, Giusca S, Ector J, Wildiers H, Van den Bogaert $\mathrm{W}$ and Voigt JU: Acute radiation effects on cardiac function detected by strain rate imaging in breast cancer patients. Int J Radiat Oncol Biol Phys 79: 1444-1451, 2011. PMID: 20605341. DOI: 10.1016/j.ijrobp.2010.01.004

55 Lo Q, Hee L, Batumalai V, Allman C, MacDonald P, Delaney GP, Lonergan D and Thomas L: Subclinical cardiac dysfunction detected by strain imaging during breast irradiation with persistent changes 6 weeks after treatment. Int J Radiat Oncol Biol Phys 92: 268-276, 2015. PMID: 25968824. DOI: 10.1016/ j.ijrobp.2014.11.016

56 HeggemannF, Grotz H, Welzel G, DöschC,Hansmann J, KrausTiefenbacher U, Attenberger U, Schönberg SO, Borggrefe M, Wenz F, Papavassiliu T and Lohr F: Cardiac function after multimodal breast cancer therapy assessed with functional magnetic resonance imaging and echocardiography imaging. Int J Radiat Oncol Biol Phys 93: 836-844, 2015. PMID: 26530752. DOI: $10.1016 /$ j.ijrobp.2015.07.2287

Received February 4, 2019

Revised February 23, 2019

Accepted February 25, 2019 